\title{
Challenges to Local Housing Policies of MigRANTS IN EUROPE
}

\author{
Hubert Krieger
}

\section{Introduction}

European cities, in particular major cities with strong economies, attract immigrants from all over the world. As a result, urban populations have become increasingly heterogeneous in ethnic, cultural, and religious terms. The housing of migrants is a central issue that affects quality of life in general. Besides finding employment and gaining access to good education it remains a crucial aspect in the process of successful structural integration of migrants in host societies. The report entitled Housing and Integration of Migrants in Europe discusses innovative policies and their implementation at the local level (Council of Europe \& Eurofound 2007) as well as examining segregation and access to affordable housing for migrants.

The housing situation of migrants in a city can be considered an important indicator of the present state of structural integration in the receiving society. Housing policies are an important part of overall social policy at the local level, with a strong impact on future processes of integration of migrants and their descendants. Many of the challenges of integration have to be dealt with at the local level. Cities and local authorities play a vital role, not only in the implementation of integration policies, but also in the development of innovative policies on housing, education, and cultural diversity.

This paper is based on findings from 20 case studies carried out as part of the first CLIP module on housing. ${ }^{26}$ The research took into account the key dimensions of local housing policies for the integration of migrants and minority groups. This article highlights key issues and puts forward recommendations for policymakers at the European, national, and local level. These recommendations are intended as input in

26 Cities that actively participate in the research include Amsterdam, Antwerp, Arnsberg, Breda, Brescia, Budapest, Copenhagen, Dublin, Frankfurt am Main, Izmir, Liège, Luxembourg, Marseille, Prague, Sefton, Stuttgart, Terrassa, Turku, Vienna, and Zagreb. 
the development of guidelines for good practice to help cities deal more effectively with the challenge of integrating migrants into the local community.

\section{CLIP Research and Method}

This article is based on research undertaken by a group of European researchers organised under the umbrella of the Euro-wide IMISCOE network of excellence ${ }^{27}$. The investigation was contracted by Eurofound in Dublin in cooperation with a group of European cities that form the CLIP network (Cities for Local Integration Policies for Migrants). Today this organization encompasses more than $35 \mathrm{EU}$ and non-EU cities. $^{28}$ The city network is supported politically by the Congress of Local and Regional Authorities of the Council of Europe (CoE), the European Foundation for the Improvement of Living and Working Conditions ("Eurofound"), the Committee of the Regions (CoR), the Council of European Municipalities and Regions (CEMR), the European Network Against Racism (ENAR), and the three cities of Stuttgart (Germany), Vienna (Austria), and Amsterdam (The Netherlands), which represent the cities in the Steering Committee of CLIP.

The CLIP network seeks to:

- support the social and economic integration and full participation of migrants,

- combat social inequalities and discrimination against migrants,

- improve the peaceful co-existence between migrants and natives and

- promote respect for the cultural identity of migrants.

27 The centers are the Institute for Urban and Regional Research (ISR) in Vienna, the Institute for Migration and Ethnic Studies (IMES) in Amsterdam, the Forum of International and European Research on Immigration (FIERI) in Turin, the Institute of International Studies (IIS) in Wrocław, the Centre for Migration Policy Research (CMPR) in Swansea and the european forum for migration studies (efms) in Bamberg which coordinates the research group. Previously also Centre for Ethnic and Migration Studies (CEDEM), University of Liège and Centre on Migration, Policy and Society (COMPAS), University of Oxford participated in the research team.

28 Amsterdam (The Netherlands), Antwerp (Belgium), Arnsberg (Germany), Athens (Greece), Bologna (Italy), Breda (The Netherlands), Budapest (Hungary), Copenhagen (Denmark), Dublin (Ireland), Frankfurt am Main (Germany), Helsinki (Finland), Hospitalet (Spain), Istanbul (Turkey), İzmir (Turkey), Kirklees (United Kingdom), Liège (Belgium), Lisbon (Portugal), Luxembourg (Luxembourg), Malmö (Sweden), Newport (United Kingdom), Prague (Czech Republic), Stuttgart (Germany), Sundsvall (Sweden), Tallinn (Estonia), Terrassa (Spain), Turin (Italy), Turku (Finland), Valencia (Spain), Vienna (Austria), Wolverhampton (United Kingdom), Wrocław (Poland), Zagreb (Croatia), Zeytinburnu (Turkey), and Zurich (Switzerland). 
It aims to achieve these objectives by bringing together European cities and fostering a joint learning process about successful integration practices. By encouraging the structured sharing of experiences through the medium of city reports and workshops, the network enables local authorities to learn from each other and, thus, to pursue a more effective integration policy for migrants. The analysis of innovative policies, carried out under the auspices of CLIP, enhances the emerging policy debate not only at the local, but also at the national and European level.

This is the first module of CLIP. The second module addressed equality and diversity in municipal employment and services provision. The network analyzed policies enhancing migrants' access to municipal jobs and progress in employment as well as cities' efforts to provide adequate services for migrants (Eurofound \& Council of Europe 2008).

The third report, finalized in 2009, focuses on intergroup relations and intercultural policies in European cities. Since the growing multicultural, multiethnic, and multireligious structures of urban populations challenge the ability of cities to secure social cohesion, cities have a genuine interest in establishing effective intercultural policies and promoting peaceful intergroup relations at the local level. The report presents and analyzes intergroup relations and intercultural policies in the CLIP cities, encouraging an exchange of experiences that furthers a learning process within the network. The fourth, and for the time being last, report of CLIP will deal with local policies supporting ethnic entrepreneurship and the employment conditions of migrants in ethnically owned companies. Fieldwork on this module will start in the Fall of 2009, and a final report can be expected by the end of 2010 .

The aim of the CLIP network is to facilitate a common research-based learning process between European cities. The research process was organized in a series of steps. First, experts from the research group compiled a concept paper suggesting an analytical framework for the module. This paper was then discussed with the steering committee and with city representatives. On the basis of these discussions, the research group refined the conceptual approach, which was then used by the research group to develop a standardized Common Reporting Scheme (CRS) for research in each city. This reporting scheme included a variety of (mainly open) questions concerning statistical information on the city and its populations, general approaches toward housing policies, objectives, city programs, and concrete activities to improve access to housing and housing conditions, and to reduce spatial segregation (second step). The reporting schemes were filled in by city officials to provide researchers with comparable data for each participating city (third step).

When the completed CRS document had been received and analyzed, the research team organised four-day field visits in each participating city (fourth step). The purpose of the field visits was to elaborate on the responses provided by the city through the CRS document. Therefore, these visits consisted of interviews and group discussions with a variety of local actors. Overall, the CLIP project aims to trigger and support a structured process of mutual exchange of experiences among the participating 
cities. Such an approach requires a bottom-up research design and involves the participating cities as actors of the ongoing CLIP project.

The housing research in the CLIP project focuses on a systematic analysis of the residential segregation and/or concentration of migrant or ethnic minority groups in European cities, and on the access of migrants to affordable and decent housing. The research looks at the situation of vulnerable groups with a migratory background. Of course, not all migrants belong to these vulnerable groups and face poor housing conditions. Thus, migrants should not generally be seen as victims unable to develop positive strategies, either individually or collectively, to improve their housing situation.

Typical challenges to migrants include a limited command of the language of the receiving country, a lower socioeconomic status, social exclusion, lack of knowledge of housing-related rights and responsibilities, as well as discrimination and exploitation in the housing market.

\section{Policy Context and Recommendations}

In two recent documents, the European Commission underlined the need at EU level to successfully manage the integration of present and future immigrants into the host societies: the Green Paper "On an EU approach to managing economic migration" (2004) and "Communication on the integration of third-country nationals in the European Union" (2005). The issue of housing for migrants was also addressed in the Commission Communication and in the second edition of the European Handbook on Integration for Policymakers and Practitioners published by the Commission in May 2007. Moreover, the ongoing discussion among the EU Member States on emerging "parallel societies" of migrants and social unrest within migrant communities, for example, in the troubled suburban communities (banlieues) of several French cities and more recently in Copenhagen in March 2007, illustrates the increasing relevance of integration issues at the EU level. This discussion is strongly related to the segregation of migrants and minority groups in European cities, which is dealt with by the CLIP research. Finally, the emerging debate on Europe's increasing demographic and labor supply challenges recognizes the importance of a successful economic migration and social integration policy for migrants and their descendents in the scope of the EU's Lisbon strategy.

Local policies on segregation and housing for migrants can in many cases be considered a strand of general social policy and city development measures. The spectrum of policy approaches can range from neoliberal and radically market-oriented interpretations of the role of municipal governments to a welfare-state-oriented perception of local government being responsible for the realization of compensatory social policy measures.

When dealing with migrants, local policy has to consider not only the challenges posed by an increasingly diverse population in terms of language acquisition and cog- 
nitive integration, it has also to take into account the risk of developing highly segregated parts of the city that become stigmatized through public opinion.

The framework for housing policy in each country and city area is shaped by both the local housing market structures and the respective legal regulations. Integration processes for migrants are promoted at the local level in cities, districts, and neighbourhoods. Each city differs with respect to its specific opportunities, challenges, and barriers, hence, general objectives concerning access to housing for vulnerable groups have to be implemented differently in order to be effective.

To solve the complex problems of migrant housing, a systematic analysis of housing needs as well as a strategic urban planning and housing policy coordinated with other policies are necessary. No single policy instrument exists that can solve all problems in relation to the housing of migrants in the local context. Rather, a wide range of potentially useful instruments and a combination of policies appear more suitable for different situations and in various local contexts. Cities must adapt their housing policy to the specific local situations - and they must also integrate this policy into their wider socioeconomic development objectives.

\subsection{Recommendations for European Policymakers}

Although the EU has no formal competence in housing under the EU Treaty, its competence for policies related to the free movement of persons and the prevention of discrimination should be applied in the area of housing as well. The Council of Europe has also made relevant contributions to the discussion on housing policies in Europe. This section presents recommendations for policymakers at the European level drawn from the CLIP research into housing.

\section{Support Networking Among Cities and Dialogue with European Policymakers}

The EU and the Council of Europe should support the networking of cities at the European level and should also include municipal administrations as stakeholders in the further development of European policies relevant to housing and the integration of migrants. In this context, it is recommended to continue activities such as the creation of a Social Platform on Cities and Social Cohesion by the Commission and to further develop the Commission's cooperation with Eurocities. The Commission should ensure an adequate participation of representatives of European cities in their planned European Integration Forum. The European Economic and Social Committee (EESC) and the Committee of the Regions should continue their activities on the integration of migrants and housing.

\section{Initiate and Finance Relevant Research}

Another important area of activities for European organizations would be to initiate relevant research programs on housing and the integration of migrants. It is suggested that the Commission's research programs in the area of social exclusion and poverty be continued, and new research programs be initiated on housing and migrants 
within the remit of activities of EU agencies such as the European Fundamental Rights Agency (FRA) in Vienna and the Foundation.

\section{Support Cities as Active Bodies and Stakeholders}

European policymakers should consider cities as active bodies and stakeholders in policy, and should stimulate and facilitate them to develop and implement policies. In this context, cities could consider applying for funding under the new Integration Fund for third-country migrants and under the Commission's new Progress program. They could also include the integration of migrants in general and integration into the local housing market in particular into the National Action Plans (NAP) for social inclusion.

\section{Integrate Public Housing into the EU Cohesion Policy}

The EU Council of Ministers has given priority to combating social exclusion related to housing, and for the first time it has made public housing eligible in the new Member States for the 2007-2013 cohesion policy. The European Parliament adopted a report in March 2007 on "Housing and Regional Policy", committing itself to a "European Declaration on Housing" based on the "European Housing Charter" proposed by 65 members of the European Parliament (MEPs) within its intergroup on "Urban Housing". On this basis, it is recommended that available funds be used for public housing to improve the situation of low-wage earners including low-income groups of migrants.

\section{Monitor the EU Directive Against Racial Discrimination}

The effectiveness of the implementation of the 2000 EU Race Directive is under discussion in several Member States. It is suggested that the European Commission monitor whether it is being implemented effectively to protect migrants from discrimination on the grounds of their race in terms of access to housing.

\subsection{Recommendations for EU Member States}

This section presents recommendations for policymakers at the national level drawn from the CLIP research into housing. Governments play a key role in formulating policies for the integration of migrants, giving public funding for urban renewal and housing projects, and tackling discrimination and segregation of migrants.

\section{Formulate a National Integration Policy}

A local policy for integrating immigrants into the housing market must be integrated into a general policy of migration and integration. This national policy should clearly define the conditions for residence.

\section{Strengthen the Scope of Action at the Municipal Level}

Measures to encourage integration related to the housing market need cities and communities to be financially empowered; thus, cities and communities should be allocated sufficient resources. National housing programs should provide cities with 
more latitude to act in ways they deem appropriate to their local circumstances. City centers tend to have fewer financial means at their disposal than suburban and regional areas. The Member States are thus called upon to ensure that cities have adequate finances for integration projects and to support the applications of municipalities for financing housing-related projects within the framework of the structural funds or the European Integration Fund.

\section{Establish Framework Conditions for the Provision of Housing}

It is recommended that EU Member States create the legal framework conditions that allow cities and communities to take on an active role in the housing market, for example, as building contractors, landlords, or property owners. They should, moreover, establish the legal framework that allows cities and communities to introduce forms of rent control if this seems desirable from the perspective of urban planning, social considerations, or economic concerns. The conditions for access to publicly supported housing should be organised in such a way that they do not indirectly discriminate against migrants.

\section{Support Affordability}

Measures to encourage integration related to the housing market should be based on a balanced mixture of offering subsidies for buildings and providing subsidies directly to people, thus increasing the affordability of housing. Offering subsidies for buildings aims to reduce the market price of housing, by offering, for example, direct support for building contractors who agree to limit the selling price or rent, or pass on distribution rights to public bodies. Subsidies allocated to individual buyers involve measures such as monthly rent allowances, tax benefits, or awarding a fixed subsidy amount. Member States should therefore create legal provisions for offering subsidies, in principle to both low-income indigenous as well as migrant groups. Repayable funding such as low-interest loans to buy new property or to renovate an existing property could, moreover, be made available.

\section{Curb the Process of Urban Devaluation}

The concentration of immigrant populations in certain sections of cities has had the self-perpetuating effect devaluing property in these areas, causing in turn an exodus of native middle-class households, a loss in spending power, and low investment in the physical structure of the city. To prevent this devaluation process, the Member States should systematically monitor the socioeconomic development in cities and urban districts in order to be able to implement countermeasures in due time such as urban-renewal projects. Public funding should be used to initiate projects and encourage private investors to become involved, though such financial incentives should also be withdrawn if urban renewal takes place of its own accord. The social mix of the population should be acknowledged and preserved as a special quality.

\section{Improve "Good Practice" in Local Governance}

Local governance structures must be improved through the participation of stakeholders and implementation of their efficiency. National policy should promote inter- 
cultural openness and diversity policies of national and local institutions, as well as promoting better cooperation and partnerships with local NGOs and welfare organizations, churches, local chambers of commerce, local trade unions, and landlords' and tenants' associations. The aim should be to avoid complex bureaucratic requirements in national housing programs and to allow for flexible customization to local needs. Governments need to support preventive measures with regard to the segregation of migrants as well as to monitor discrimination and support anti-discrimination measures.

\subsection{Recommendations for Local Policymakers}

The following recommendations for local policymakers bring together specific experiences made in various cities as well as innovative ideas put forward in several cities within the CLIP network. In general, these recommendations are applicable to all European cities. For the actual implementation of a particular measure or policy, however, the appropriate adaptation to local characteristics is a precondition for the success of an initiative.

\section{Partnership and Cross-Departmental Cooperation}

Given the complex interrelationship of policies targeting housing issues, the integration of migrants, and other municipal areas, an integrated, cross-departmental approach is strongly recommended. A central coordination unit should be established within the local administration for the integration policy regarding migrants. This unit would be responsible for informing and being informed by all departments, participating in integration programs, and preparing decisions. Such collaboration within the municipal administration should be accompanied by full cooperation and strong partnerships with local bodies, such as NGOs, welfare organizations, churches, chamber of commerce, unions, as well as associations representing landlords and tenants. Examples of such transversal cooperation would be regular internal working groups between relevant departments of the local administration, including institutions dealing with issues relevant to housing, urban planning, social affairs and welfare, health, youth, integration and diversity, education and law enforcement; or regular roundtables and meetings with external experts and representatives of civil society dealing with housing and migrant-integration issues. These initiatives should be embedded in a long-term integration policy with a holistic approach to housing.

\section{Reliable and Up-to-Date Information}

In order to plan and implement local integration policies and policies relevant to housing and segregation, local policymakers and administrators need reliable, comprehensive, and up-to-date information. This would include pertinent data on migrants living in the city, such as the number of migrants, the age structure of the migrant population and typical household sizes, the migrants' national and ethnic background, as well as their legal status. A city should not only deal with persons of foreign citi- 
zenship, but also consider individuals with a "migratory background", such as secondand third-generation migrants.

In addition, information on housing conditions and the spatial distribution of migrants (segregation indices) could form the basis for appropriate measures and for the development of a preventive and sustainable housing policy. For this reason, city administrations should collect information on migrant movement in a city through flow data, and develop indicators to monitor and evaluate the current housing situation of migrants, including size and quality of accommodation, as well as indicators to evaluate migrants' access to housing, such as the waiting period for public housing of migrants versus that of indigenous population groups.

This information should be part of an overall monitoring of the quality of life of migrants in the community. Data collection would rely on a variety of sources such as general population surveys, local population data, scientific studies, and opinion surveys. Own data collections could be considered if the existing sources do not refer to the migrant status or are otherwise insufficient.

\section{Access to Public Housing}

To ensure decent housing for low-income groups in particular, the supply and provision of access to affordable public housing is vital. As far as the integration of migrants is concerned, local authorities should consider the specific market position of migrants with regard to supply, access, and affordability of housing, as well as the degree of spatial segregation and the extent of discrimination.

Because of the undersupply of public housing and strong competition between native and migrant low-income earners, access to public housing often represents a major issue for local policymakers. To enhance adequate access to public housing for everyone in need while also securing neighbourhoods that are socioeconomically and ethnically mixed, city authorities should clearly set out the requirements and regulations for obtaining access to public housing, such as maximum family income, waiting period, and children or elderly family members in need of care in the household, as well as establish a ranking list and emergency provisions enabling people waiting for public housing to jump the queue in case of urgency. Access for migrants can be enhanced by providing up-to-date and relevant information on available public housing, in different languages as necessary.

The aim should be to achieve mixed neighbourhoods. There are various ways to do this, for example, by opening access to public housing to middle-class households or by defining explicit or implicit quotas for migrants in public housing. However, the legality and efficiency of such quotas have to be carefully considered. Equally, opening up the public-housing market to middle-class income earners might contradict the basic rationale of providing affordable public housing.

\section{More Efficient Housing Cooperatives}

Most of what has been said regarding access to public housing also holds true for housing associations, in which the associates are the owners. In this case, while com- 
petition between native and migrant tenants or owners seems to be even stronger, the local authorities' influence over the allocation of housing to migrants is lower. To improve this situation, authorities should provide municipal property to housing associations in exchange for a controlled level of rents and a certain quota of apartments for which the city has the right to assign tenants. They could also coordinate the provision of housing for migrants among housing associations by establishing a roundtable. Authorities could, where possible, abolish existing formal regulations or informal practices in housing associations which discriminate migrants against indigenous population groups, for example, waiting lists requiring a long period of residence or provisions for inheriting residence rights.

\section{Access to Local Housing Market}

Because of the many challenges inherent in the process - a lack of command of the receiving country's language, lack of knowledge of housing-related rights and responsibilities, as well as discrimination and exploitation on the general housing market migrants often experience difficulties finding appropriate housing, particularly new and recent arrivals to a country. City administrations can support access to the housing market through better provision of information and systematically monitoring discrimination. They can set up low-threshold, "one-stop" citizens advice centers, where migrants can obtain advice and information on the local housing market and get help in intercultural conflicts, as well as obtaining information on financial and legal issues, such as rent payment, rent index, extortion, rent-related debts, legal period of notice, and other obligations and rights. Administrations should also consider the establishment of an ombudsman to collect complaints, make recommendations, and systematically monitor discrimination of migrants on the housing market. Information leaflets should be available in various languages, and applicants should be put in touch with volunteer mentors or migrant associations of the same language group.

\section{Measures Against Overcrowding}

Several cities have reported situations in which migrants were exploited by private landlords. The problem of voluntary overcrowding in privately rented housing to keep down the rents also poses a serious challenge for migrants. To tackle this challenge, national governments need to review the control mechanisms and resources available to local authorities to deal with such issues, for example, a licensing system for private landlords with properties in multiple occupations. Local authorities could work in partnership with other agencies that have the authority to enter such properties, so that they share information on unacceptable housing conditions and take joint action to address the situation.

\section{Public-Private Partnerships}

In order to improve access and affordability for migrants to privately rented housing, city administrations could consider innovative public-private partnerships (PPPs). One way of doing this would be to act as contractor by renting private property below market price and subletting these low-priced apartments to migrants - private owners 
generally accept a lower rent in exchange for a rent guarantee spanning several years and a guarantee to preserve the quality of the accommodation. Another means would be to provide municipal property at below-market prices to private builders or developers, who in turn have to offer a certain share of the apartments at reduced rents to target groups like families with children. Similarly, local authorities could act as a mediator in contracts between tenants with migratory background and owners who may be nationals, while providing the guarantee to the owner, for instance, that potential damages caused by the tenant will be repaired.

\section{Affordable Home Ownership}

While publicly or privately owned rented accommodations still dominate the housing market in some European cities, other housing markets in Europe are dominated by owner-occupied housing. This structure leaves migrant families, who want to stay for a longer period of time, often no other choice than to buy a house in order to find appropriate accommodation. Migrants, often in a more socioeconomically disadvantaged situation than the indigenous population, cannot easily afford to buy a house.

However, since home ownership often improves the housing conditions of migrant families and can be considered as a major step toward integration into the receiving society, it should actively be promoted. Local authorities can support this process by offering subsidies or tax breaks to low-income families, including migrants, for building new houses or purchasing and renovating existing housing. They could also provide municipal property at a subsidized price to low-income families who would build houses on that property, as well as to private developers, who in turn have to sell housing units below market price to target groups. Another way to support this process is to facilitate access to mortgages at reduced interest rates in cooperation with local banks, for example, by providing the bank with a guarantee for default by private organizations. Local authorities should also consider enabling migrants to contribute to the construction of their house through their own labor and support their involvement in housing cooperatives.

\section{Better Personal Security}

City administration should always aim to improve the level of personal security in neighbourhoods with a poor infrastructure, a sizeable proportion of residents with low socioeconomic status, and/or a high proportion of migrants. Establishing a structured and continuous dialogue between local police officers and migrants would go a long way toward achieving this goal. As part of this process, police should receive training in intercultural competence. Having specially trained community police officers helps to increase the indispensable involvement on the part of the migrant community. Their contribution in this process could include, for example, having "neighbourhood fathers" who moderate the behaviour of youngsters from migrant families and thus help prevent provocative acts and petty crime by local youth gangs. Authorities should aim to maintain regular cooperation between schools, police, and social services in an effort to reduce crime. There should be low-threshold provisions for reporting hate 
crime against migrants, and to overcome the problem of migrants being too fearful to go to the police station an independent place separate from the police station should be available where people can report such crimes.

\section{Soft Urban Renewal}

Urban renewal - the physical rehabilitation of impoverished urban neighbourhoods by renovation and (re)construction of housing and public infrastructure - is often not sufficient for the rehabilitation of deprived areas with a high concentration of migrants and low-income indigenous population groups. Hence, some CLIP cities have developed a more innovative approach: They go beyond physical renovation measures supporting "soft urban renewal", which takes social, economic, and cultural demands into consideration, and where the planning and implementation process is directly influenced by the residents. In such a process, existing housing stock can be reconverted and upgraded instead of demolished, and new public spaces can be built or modernized. Public services like libraries, municipal offices, and university buildings can be allocated to these neighbourhoods. Local authorities could try to improve the employment and economic opportunities for low-income and unemployed citizens in deprived districts, including the promotion of local ethnic entrepreneurship. A challenge remains how to attract new middle-class families to the renewed areas while retaining the long-term residents, some of whom have a migrant background.

\section{Anti-Segregation Policy}

The city administrations participating in the CLIP project believe that a high concentration of migrants, particularly of one ethnic group of migrants, should be avoided, since this hinders the successful integration of other migrants. A mixture of different types of housing and different ethnic groups with the native population is recommended, as a balanced socioeconomic and demographic composition is regarded as constituting an important aspect of any anti-segregation policy. In particular, efforts should be made to spread public housing across the city, to build smaller public housing units, and to retain the middle-class native population in areas with a high concentration of migrants in order to achieve a social mix. Such areas should have adequate provisions for childcare services, schools, and sports facilities in order to enhance the integration of this area into the city as a whole and hence reduce segregation patterns. Urban renewal programs can help to create socioeconomically mixed neighbourhoods. Finally, authorities could improve the image of the neighbourhood in the media and among the general public by using an effective communication strategy and organizing cultural or sports events.

Whenever aiming to achieve more balanced neighbourhoods, local policy often uses formal or informal quotas to avoid a high concentration of migrants. Quota regulations must be checked with regard to their effectiveness, fairness, and legality. Voluntary measures might achieve more in this context: Instead of attempting to control the inflow of migrants into neighbourhoods, a more successful approach could be to support measures that encourage the native population to stay. 


\section{Ethnic Enclaves}

Generally, the research recommends promoting neighbourhoods that are ethnically and socio-economically mixed. However, the CLIP network is also aware that some concentration of ethnic groups cannot and need not be avoided entirely. Ethnic networks can serve an important function, in particular for new arrivals who are unfamiliar with local conditions. Local administrations should support migrant organizations at the neighbourhood level and maintain regular contact with them. They should also integrate such neighbourhoods as far as possible into the city as a whole by providing the necessary infrastructure and services and maintaining a positive dialogue. They should carefully monitor the mobility of migrant and native population to avoid undesirable outcomes.

\section{Community Relations and Participation}

Good community relations - that is, relations between differing groups in a community - are an important factor determining the quality of housing for both migrants and indigenous residents in an area. The participation and involvement of local residents in activities and projects contribute strongly to good community relations. This can be achieved by the effective and early participation in the planning process of measures and projects and the establishment of neighbourhood action groups. Support should be given for local associations and their activities, as well as the involvement of migrants in owners' associations.

\section{Bibliography}

Council of Europe and European Foundation for the Improvement of Living and Working Conditions (2007), Housing and integration of migrants in Europe, Dublin. (http://www.eurofound.europa.eu/publications/htmlfiles/ef0794.htm).

Council of Europe and European Foundation for the Improvement of Living and Working Conditions (2008), Equality and diversity in jobs and services: City policies for migrants in Europe. Dublin.

European Commission (2007, May), European handbook on integration for policymakers and practitioners (second edition). Luxembourg: Office for Official Publications of the European Communities. (http://ec.europa.eu/justice_home/doc_centre/immigration/integration /doc/2007/handbook_2007_en.pdf).

European Commission (2005, September), A common agenda for integration - Framework for the integration of third-country nationals in the European Union, $\operatorname{COM}(2005) 389$ final. Brussels. (http://eur-lex.europa.eu/LexUriServ/site/en/com/2005/com2005_0389en01.pdf).

European Commission (2005, January), Green Paper on an EU approach to managing economic migration, $\operatorname{COM}(2004) 811$ final. Brussels.

(http://ec.europa.eu/justice_home/doc_centre/immigration/work/doc/com_2004_811_en.pdf).

European Economic and Social Committee (2005), Information Memo (own-initiative opinion), EESC own-initiative opinion on Immigration in the EU and integration policies: cooperation between regional and local governments and civil society organizations. Brussels. 
Organisation for Economic Cooperation and Development (OECD) (2007), Competitive cities: a new entrepreneurial paradigm in spatial development. Paris.

Organisation for Economic Cooperation and Development (OECD) (2006), Competitive cities in the global economy, OECD Territorial Reviews. Paris. 